\title{
Effect of neck range of motion exercises on neck disability and pain among patients undergoing thyroidectomy
}

Om Elhana Kamel Abo Shehata, Omima Said M.H. Shehata, Seham Mohamed Abd Elalem*

Medical Surgical Nursing Department, Faculty of Nursing, Menoufia University, Egypt

Received: June 14, 2020

DOI: $10.5430 / \mathrm{cns} . v 8 \mathrm{n} 4 \mathrm{p} 1$
Accepted: September 2, 2020

Online Published: September 17, 2020

\begin{abstract}
Objective: Thyroidectomy is a surgery in which head and neck became extended during operation to facilitate surgical performance. Patients experience neck pain and limitation to the range of motion following surgery. The study's aim was to assess the effect of neck range of motion exercises on neck disability and pain among patients undergoing thyroidectomy.

Methods: A quasi-experimental research design was utilized, the research was carried out at the surgical department in Shebin Emergency Hospital, at Shebin El-Kom District, Menoufia Governorate, Egypt. Sample; 90 adult subjects undergoing thyroidectomy and are welcoming to participate in the current research. Four Instruments for data collection: Instrument (1): Interview questionnaire sheet consists of two parts to assess subjects' socio-demographic and medical data. Instrument (2): Visual analog pain scale to rate the patients' level of pain intensity. Instrument (3): Neck disability index to assess neck pain and its effect on patients' ability to perform daily activities. Instrument (4): Compliance assessment sheet to follow the patient's adherence with neck range of motion exercise.

Results: There was no statistically significant difference found between study and control group socio-demographic characteristics and medical history while there was a statistically significant difference between study and control group concerning neck disability and pain after one week and four weeks post-operative thyroidectomy.

Conclusions: Patient compliance with a range of motion exercises significantly improves neck movement in order to be able to carry out daily life activities and reducing pain for the study group in comparison with the control group.

Recommendation: Nurses who work in the general surgery department should include a neck range of motion exercises in providing the care and follow up protocol for the patients undergoing thyroidectomy.
\end{abstract}

Key Words: Range of motion exercises, Neck disability, Pain, Thyroidectomy

\section{INTRODUCTION}

All over the world, an estimated 4,511 surgeries every 100,000 population occur each year, equating to one surgical procedure annually for every twenty-two people. ${ }^{[1]}$ Thyroidectomy is a very common surgical procedure worldwide and is one of the most common interventions in endocrine surgeries. It has increased three times over the past three decades between 118,000 to 166,000 cases in the United States (US) undergoing thyroid surgery every year for benign or malignant disorders. ${ }^{[2,3]}$ Thyroid surgery shows the main treatment method for both benign and malignant thyroid diseases, such as symptomatic goiter, hyperthyroidism, thyroid

\footnotetext{
*Correspondence: Seham Mohamed Abd Elalem; Email: ahmed_said2223@yahoo.com; Address: Medical Surgical Nursing Department, Faculty of Nursing, Menoufia University, Egypt.
} 
nodules, and thyroid cancer. ${ }^{[4,5]}$ Approximately 54,000 thyroid cancer cases were diagnosed in 2018 , matching to $3.1 \%$ of total new cases of cancer confirmed during that year and the twelve leading type of cancer in the US, this main leading cause for thyroidectomy because thyroid nodules, which can give rise to thyroid cancer as many as $68 \%$ of healthy adults have thyroid nodules that have significantly increased the number of surgeries and biopsies carried out in the US. ${ }^{[6,7]}$ Randolph and Shah ${ }^{[8]}$ added that other indications for thyroidectomy include cosmetic when the thyroid gland is a very enlarged, or symptomatic obstruction when the thyroid gland is causing difficulties in swallowing or breathing.

However, thyroidectomy has four different types and one of the most common surgical procedures carried out all over the world, it has many potential complications or sequelae such as some permanent complications which may impact dramatically on the patient's quality of life (QOL). ${ }^{[6,9]}$

Post thyroidectomy, the patients have postoperative occipital headaches, posterior neck pain, neck and shoulder movement problems, stiffness in the shoulders, and limitation of cervical spine range of motion as a result of the fixed position of neck during and after thyroidectomy surgery. These previous mentioned complains may be occurred for a long-time following surgery and may affect negatively on the patients' quality of life. ${ }^{[10]}$

Pain from thyroidectomy is due to two reasons. The first is a result of the wound of the surgery and patient localized it at the surgical incision. the second is positional posterior neck pain that result from hyperextension of the patient's neck during surgical procedure because the patient is put in the supine position with neck extension in order to provide better access to surgical site and facilitate the surgical operation. Therefore, the type of pain can be easily differentiated following surgery. ${ }^{[4,11]}$

Recently, a variety of treatment modalities have been utilized following head and neck surgeries to overcome these annoying complaints like a preoperative bilateral greater occipital nerve block, bilateral superficial cervical plexus block combined with a bilateral greater occipital nerve block, and intraoperative transcutaneous electrical nerve stimulation as well as postoperative neck stretching exercise. ${ }^{[12]}$

Nurses play an important role in educating patients about the signs and symptoms of potential complications, also should assess pain severity and educate patient neck range of motion should be maintained even the patients have the ability to move their head and neck freely. In addition to, written and verbal information concerning medications, care of surgical wound, nutrition, and follow-up visits with the physician. ${ }^{[13]}$ The nurses should encourage patients to move stretch their shoulders and neck slowly and completely because this is the simplest and effectively exercise to decrease pain and muscle weakness, improve functionality and flexibility level of the patients. ${ }^{[14]}$

Jacobs ${ }^{[15]}$ and Terris, Snyder \& Carneiro-Pla ${ }^{[16]}$ reported that neck movements and neck stretching exercises are recommended to avoid negative experiences following thyroidectomy. The basic neck stretching exercises will improve pain perception in patients by improving neuromuscular coordination and muscle weakness can be prevented.

\subsection{Significance of the study}

From the researchers' experience, it has been observed that the most of thyroidectomy patients complaining from neck disability and pain postoperatively due to neck stiffness as a result of the position of the head and the neck that becomes extended during the operation which necessary to facilitate the surgical performance, so patients have impaired in neck movement for a long time that has a negative effect on them. also, it has been observed during daily clinical practice that the patients were not having adequate knowledge about neck range of motion exercise and the advantages of practicing this exercise to reduce the neck disability and pain although it clears that the range of motion exercise plays an important role for improving the function of the neck. So, the researchers hope that the research assesses the effect of neck range of motion exercises on neck disability as well as pain among patients undergoing thyroidectomy.

\subsection{Research aim}

The research aim was to assess the effect of neck range of motion exercises on neck disability and pain among patients undergoing thyroidectomy.

\subsection{Operational definition}

Neck range of motion exercises defined as the maximum movement that is possible for neck joint in natural directional movement (flexion, extension, lateral flexion, and rotation) for increasing neck movement while reducing stiffness and pain. ${ }^{[17]}$

\subsection{Research Hypothesis}

(1) Disability in neck movement will be less than in the study group patients who perform neck exercises than the control group.

(2) The pain level will be less than in the study group patients who perform neck exercises than the control group. 


\section{Methodology}

\subsection{Design}

A quasi-experimental research design was used.

\subsection{Setting}

General surgical department and surgical outpatient clinic of Shebin Emergency Hospital, at Shebin El-Kom District Menoufia Governorate, Egypt.

\subsection{Sample}

The type of sample was purposive of ninety patients who entered the surgical department for thyroidectomy and welcome to share in the research and fulfill the inclusion criteria. The study patients were divided randomly and alternatively into two equal groups forty-five patients in everyone as the following:

Study group (I): received neck range of motion exercise and routine nursing care in the hospital.

Control group (II): received only routine nursing care in the hospital.

Exclusion criteria: Patients had diagnosed with thyroid cancer, neck pain or cervical problems before the operation, neck dissection during thyroidectomy, neck drains during the thyroidectomy because interfering with neck movements and can dislocate with affecting the suture and cause pain, Psychological and mental problems, as well as rheumatic or orthopedic conditions of the neck as cervical osteomalacia.

Calculation of the sample size: The required sample size was equal to ninety patients depend on Equation 1, sample size (n) was at $95 \%$ level of confidence and a study power of $95 \%$ :

$$
n=\frac{D E E F \times N p(1-p)}{\frac{d_{2}}{Z_{2}}-\frac{\alpha}{2} \times(N-1)+p \times(1-p)}
$$

\subsection{Instruments of the research}

Four instruments were used by the researchers that needed for the collection of the necessary data and achieve the aim of the current research.

Instrument (1): Interview questionnaire sheet

It was constructed by the researchers to assess subjects' sociodemographic and medical data. It divided into two parts:

Part one: Patients' Sociodemographic data: it included subjects' socio-demographic data related to age, gender, marital status, education level, working, residence, and monthly income.

Part two: Patients' medical history and daily habits: it inPublished by Sciedu Press cluded the following; history for medical disease as diabetes mellitus, heart disease, hypertension, kidney disease, chronic obstructive pulmonary disease (COPD), asthma, and operation type. Daily habits as drinking tea and coffee, cigarette smoking, and exercise practices.

Instrument (2): Visual analog pain scale: It was developed by Bain, Kuwahata, Raymod, and Foster, ${ }^{[18]}$ to categorize the patients' pain intensity level. The total scale score was from $0-10$ score. $0=$ no pain, 1 to $3=$ mild pain, 4 to $6=$ moderate pain, 7 to $10=$ severe pain.

Instrument (3): Neck disability Index:

It was developed by Vernon and Mior, ${ }^{[19]}$ which is designed to understand how much neck pain has affected the patient's ability to carry out daily activities. The index has ten items regarding the intensity of pain and everyday activities such as lifting, personal care, headache, reading, work status, concentration, driving, recreation, and sleeping. every item is scored out of zero to five, a score of zero refers to no disability response so the giving total score is out of zero to 50 , higher scores represent greater disability. The Scores categorize as the following: 0-4 = no disability, 5-14 = mild disability, 15-24 = moderate disability, 25-34 = severe disability as well as, above $34=$ complete disability.

Instrument (4): Complaince assessment sheet

It was constructed by the researchers to follow the patient's adherence to the neck range of motion exercise. It includes eight items; each item score ranges from 0 (Non-compliance), 1 (partial compliance) and 2 (complete compliance) and total scores range from 0 to 16 and categorized as following; less than $50 \%$ (less than 8 ) considered non-compliance, from $50 \%$ to less than $75 \%$ from 8 - less than 12 considered partial compliance and $75 \%$ to $100 \%$ (from 12 to 16 ) considered complete compliance.

\section{METHODS}

Formal approval: Taking an official letter from the Faculty of Nursing, Menoufia University, to the director of the University Hospital, Shebin El-Kom, Menoufia, by agreeing to conduct the research in the Department of General Surgery.

Ethical considerations and patients' rights: After obtaining approval for the research application The researchers selected the patients who had the inclusion criteria and informed them about the aim of the present research to obtain their acceptance to participate in the study. Written consent was taken from the patients. The patient's confidentiality and anonymity were assured.

Validity: Illustrated the degree to which the instrument mea- 
sures what it was expected to measure, so in the current research, the questionnaire's content validity was determined by a group of experts in the field of medical-surgical and general surgery to assure relevance, coverage, completeness of the content and clarity of the questions then the required modification was applied accordingly.

Reliability: A test-retest method and a person correlation coefficient formula were utilized; it was 0.92 for the instrument (1) and 0.87 for the instrument (4). The interval between every test was 2 weeks. The reliability for Instrument (2) was tested by Boonstra, et al. ${ }^{[20]}$ and was 0.84. Also, the reliability for Instrument (3) was tested by Macdermid, et al. ${ }^{[21]}$ and was 0.98 .

Pilot study: Ten percent of the sample was taken in the pilot study to assess the clarity and the feasibility of the instruments and determine the required time to answer the questions. Depend on its result changes were conducted. The pilot study patients were excluded from the study.

Data collection for the current research was conducted through a period of time from the first of May 2019 to the end of January 2020 in the general surgical department and general surgical outpatients' clinic. Then, the collection of data was conducted over four phases: a) assessment, b) planning c) implementation d) evaluation.

\section{(1) Assessment phase}

The purpose of the current phase is to collect a basic information related to patient's demographic and medical data before the surgical performance by using instrument (1). Patients were assessed for neck pain by the researchers via instrument (2), neck disability level was assessed by instrument (3) and patient compliance to neck exercise program was assessed by using instrument (4). The researchers have conducted fifth assessments for study and control group: 1st assessment considered as a base line information before the surgical performance by using instrument (1) only, 2nd assessment in the morning first day postoperatively, 3rd assessment in 3 days postoperatively, 4 th assessment in one week postoperatively, and 5th assessment in 1 month postoperatively by using instrument (2), (3) and (4).

\section{(2) Planning phase}

The researchers go through extensive literature to construct the plan for the interventions and preparing the range of motion exercise brochure that the researchers will use it as well as demonstration and return demonstration for the patient teaching.

\section{(3) Implementation phase}

In this phase, the researchers started to learn the neck range 4 of motion exercises at the preoperative period for study group only and patients did return demonstration to sure that patients performed it competently, the teaching session taking from 30-45 minutes. The neck range of motion exercises described as the following: The nursing care included assessing neck pain and range of motion (neck exercise) through asking the patient to apply neck stretching exercise that was described to the patient during the preoperative period with colored booklet included; Try to sit and stand upright with head up and shoulders \& upper back pulled back and down, turns the head to look over one shoulder until patient feel the beginning of a stretch; hold for 3 to 5 counts and return to the middle; Then turn head towards the other shoulder. Repeat 5 to 10 times to each side, keeping shoulders still. Tilt head to one side until the patient feel the beginning of a stretch; Hold for 3 to 5 counts, return to the middle then tilt to the other side. Repeat 5 to 10 times to each side, keeping chin pointing forwards and shoulders still, Gently bend head forward and lowering chin towards chest, Return to the middle and then gently raise the chin, tilting head back, to look up, only go as far as possible until feeling the beginning of a stretch to start with. Once the wound is fully healed patients can stretch a bit more and consider holding the stretch for a few counts, roll shoulders forwards and then backward 5 to 10 times each, and sit upright, squeeze shoulder blades back and together, hold for 5 to 10 counts and then relax, exercising 2 to 3 times a day for 5 to 10 minutes. ${ }^{[21]}$

The study group was asked to perform all neck range of motion exercise, 3 times every day (morning, afternoon, and evening) for 5 to 10 minutes. All the treatment sessions were observed and the patients were given feedback on how they applied these exercises. At the discharge time, the patients have been given an exercise brochure and advised with home exercise. The patient follows up was done by telephone to identify patient compliance to exercise and in surgical out patient's clinic to assess their pain and neck disability level.

Evaluation phase "Post-test": In which, patients were evaluated for the neck disability level, level pain, and compliance with neck range of motion exercises. The evaluation was done for all patients four times, 1st time of evaluation in the morning first day postoperatively; 2nd time of evaluation in 3 days postoperatively; 3rd time of evaluation in one week postoperatively; 4th time of evaluation in 1 month postoperatively by using an instrument (2), (3) and (4). After that, the comparison between the study and control group was performed by utilizing a suitable statistical analysis.

\subsection{Statistical analysis}

Data were coded and transformed into a specially constructed format appropriate for computer feeding. All entered data 
were verified for any mistakes. Data were analyzed by utiliz- highly statistically significant.

ing a statistical package for social sciences software (SPSS) version 20 windows and were shown in tables and graphs. Two types of statistics were:

(1) Descriptive statistics were presented as number and percentage (No \& \%) for qualitative data or mean and standard deviation $(\bar{X} \pm S D)$ for quantitative data.

(2) Analytic statistics

(a) Pearson Chi-square test $\left(\chi^{2}\right)$ : its significance utilized to study correlation between two qualitative variables.

(b) Student $t$-test: its significance utilized to compare between two independent groups of normally distributed quantitative variables.

(c) Pearson's correlation coefficient $(r)$ : its significance utilized to describe the direction of the correlation between two quantitative continuous variables.

(d) $P$-values as the following: $p>.05$ is statistically insignificant, $p \leq .05$ is statistically significant, and $p \leq .001$ is a

\section{Results}

Table 1 illustrates the distribution of socio-demographic characteristics of studied groups patients. It showed that the mean age was $(39.82 \pm 10.99$ and $38.93 \pm 10.88)$ years old for the study and control groups respectively. Regarding sex, about two-thirds of studied subjects were female $(75.6 \%$ \& $71.1 \%$ ) for study and control groups respectively. About twothirds of the study and control groups were married $(71.1 \%$ $\& 66.7 \%$ ). considering the level of education about half of the patients had a secondary level of education (42.3\%) and $(51.1 \%)$ for study and control groups respectively. The majority of the studied sample, $60 \%$ for the study group, and $55.6 \%$ for control group were worker. More than half of the studied groups, $64.4 \%$ for the study and $60 \%$ for the control coming from urban areas. Concerning income levels more than half of the studied groups $(68.9 \%)$ for the study and $(62.2 \%)$ for control had middle income. There were no statistically significant differences between study and control groups in relation to sociodemographic characteristics.

Table 1. Sociodemographic characteristics of the studied group subjects

\begin{tabular}{|c|c|c|c|c|c|}
\hline \multirow{2}{*}{$\begin{array}{l}\text { Sociodemographic } \\
\text { characteristics }\end{array}$} & \multicolumn{2}{|c|}{ Study group $(n=45)$} & \multicolumn{2}{|c|}{ Control group $(n=45)$} & \multirow{2}{*}{$\begin{array}{c}\chi^{2} \\
p \text {-value }\end{array}$} \\
\hline & No. & $\%$ & No. & $\%$ & \\
\hline Age/years $(\overline{\mathbf{X}} \pm S D)$ : & \multicolumn{2}{|c|}{$39.82 \pm 10.99$} & \multicolumn{2}{|c|}{$38.93 \pm 10.88$} & $\begin{array}{c}t \text {-test }=0.39 \\
\text { p-value } \geq .05\end{array}$ \\
\hline \multicolumn{6}{|l|}{ Gender } \\
\hline Male & 11 & 24.4 & 13 & 28.9 & 0.23 \\
\hline Female & 34 & 75.6 & 32 & 71.1 & $>.05$ \\
\hline \multicolumn{6}{|l|}{ Marital state } \\
\hline Single & 6 & 13.3 & 3 & 6.7 & \\
\hline Married & 32 & 71.1 & 30 & 66.7 & 3.84 \\
\hline Divorced & 4 & 8.9 & 10 & 22.2 & $>.05$ \\
\hline Widow & 3 & 6.7 & 2 & 4.4 & \\
\hline \multicolumn{6}{|l|}{ Education level } \\
\hline Illiterate & 15 & 33.3 & 12 & 26.7 & 0.77 \\
\hline Secondary education & 19 & 42.3 & 23 & 51.1 & $>.05$ \\
\hline Higher education & 11 & 24.4 & 10 & 22.2 & \\
\hline \multicolumn{6}{|l|}{ Working } \\
\hline Has work & 27 & 60.0 & 25 & 55.6 & 2.18 \\
\hline Don't work & 18 & 40.0 & 20 & 44.4 & $>.05$ \\
\hline \multicolumn{6}{|l|}{ Residence } \\
\hline Urban & 29 & 64.4 & 27 & 60.0 & 0.19 \\
\hline Rural & 16 & 35.6 & 18 & 40.0 & $>.05$ \\
\hline \multicolumn{6}{|l|}{ Income state } \\
\hline Middle income & 31 & 68.9 & 28 & 62.2 & 0.66 \\
\hline Low income & 14 & 31.1 & 17 & 37.8 & $>.05$ \\
\hline
\end{tabular}


Table 2. Patients' medical history and daily habits for study and control groups

\begin{tabular}{|c|c|c|c|c|c|}
\hline \multirow[t]{2}{*}{ Medical history and daily habits } & \multicolumn{2}{|c|}{$\begin{array}{l}\text { Study group } \\
\quad(\mathrm{n}=45)\end{array}$} & \multicolumn{2}{|c|}{$\begin{array}{c}\text { Control group } \\
(n=45)\end{array}$} & \multirow{2}{*}{$\begin{array}{c}\chi^{2} \\
p \text {-value }\end{array}$} \\
\hline & No. & $\%$ & No. & $\%$ & \\
\hline \multicolumn{6}{|l|}{ 1. History for medical diseases: } \\
\hline \multicolumn{6}{|l|}{ Diabetes mellitus } \\
\hline Yes & 10 & 22.2 & 15 & 33.3 & 1.39 \\
\hline No & 35 & 77.8 & 30 & 66.7 & $>.05$ \\
\hline \multicolumn{6}{|l|}{ Hypertension } \\
\hline Yes & 26 & 57.8 & 18 & 40.0 & 2.85 \\
\hline No & 19 & 42.2 & 27 & 60.0 & $>.05$ \\
\hline \multicolumn{6}{|l|}{ Heart disease } \\
\hline Yes & 10 & 22.2 & 11 & 24.4 & 0.06 \\
\hline No & 35 & 77.8 & 34 & 75.6 & $>.05$ \\
\hline \multicolumn{6}{|l|}{ Kidney disease } \\
\hline Yes & 13 & 28.9 & 12 & 26.7 & 0.05 \\
\hline No & 32 & 71.1 & 33 & 73.3 & $>.05$ \\
\hline \multicolumn{6}{|l|}{ COPD } \\
\hline Yes & 5 & 11.1 & 11 & 24.4 & 2.74 \\
\hline No & 40 & 88.9 & 34 & 75.6 & $>.05$ \\
\hline \multicolumn{6}{|l|}{ Asthma } \\
\hline Yes & 11 & 24.4 & 9 & 20.0 & 0.26 \\
\hline No & 34 & 75.6 & 36 & 80.0 & $>.05$ \\
\hline \multicolumn{6}{|l|}{ Types of thyroidectomy operation } \\
\hline Total thyroidectomy & 17 & 37.8 & 19 & 42.2 & 0.19 \\
\hline Subtotal thyroidectomy & 28 & 62.2 & 26 & 57.8 & $>.05$ \\
\hline \multicolumn{6}{|l|}{ 2. Daily habits: } \\
\hline \multicolumn{6}{|l|}{ Drinking tea and coffee } \\
\hline Yes & 39 & 86.7 & 34 & 75.6 & 1.81 \\
\hline No & 6 & 13.3 & 11 & 24.4 & $>.05$ \\
\hline \multicolumn{6}{|l|}{ Cigarette smoking } \\
\hline Yes & 7 & 15.6 & 10 & 22.2 & 0.65 \\
\hline No & 38 & 84.4 & 35 & 77.8 & $>.05$ \\
\hline \multicolumn{6}{|l|}{ Exercise practicing } \\
\hline Yes & 11 & 24.4 & 8 & 17.8 & 0.60 \\
\hline No & 34 & 75.6 & 37 & 82.2 & $>.05$ \\
\hline
\end{tabular}

Table 2 reveals patients' medical history and daily habits for study and control groups. It showed that in relation to medical history more than half of the study group (57.8\%) had hypertension and (40\%) control group complained from hypertension. Concerning to type of thyroidectomy operation more than half of the study and control groups $(62.2 \%$ and $57.8 \%$ ) respectively had a subtotal thyroidectomy. Regarding daily habits, more than two-thirds of the study and the control groups were drinking caffeinated beverages like tea and coffee $(86.7 \%$ and $75.6 \%)$, didn't smoke cigarettes
(84.4\% and $77.8 \%)$, didn't do exercise $(75.6 \%$ and $82.2 \%)$ for the study and the control groups respectively. There were no statistically significant differences between the study and the control groups in relation to patients' medical history and daily habits.

Table 3 represents neck disability levels of study and control group at different times of evaluation. The table showed that more than half of the study group (57.8\%) and control group (66.7\%) had complete neck disability at the first time of evaluation, also more than half of the study group (55.6\%) 
and the control group $(66.7 \%)$ had severe neck disability at the second time of evaluation. There were no statistically significant differences between the study and the control group at the first and the second time of evaluation as $p$-value $>.05$. While at the third time of evaluation, more than half of the study group $(62.2 \%)$ had a moderate neck disability level and less than half of the control group (40\%) had moderate neck disability, and at the fourth time of evaluation, more than half of the study group (60\%) had mild neck disability, and (6.7\%) had severe neck disability, in contrast, to the control group (13.3\%) had mild neck disability and $(31.1 \%)$ had severe neck disability. The difference between the study and the control group at the third and the fourth time of evaluation was statistically significant as $p$-value $<.05$.

Table 3. Neck disability levels of study and control groups at different times of evaluation

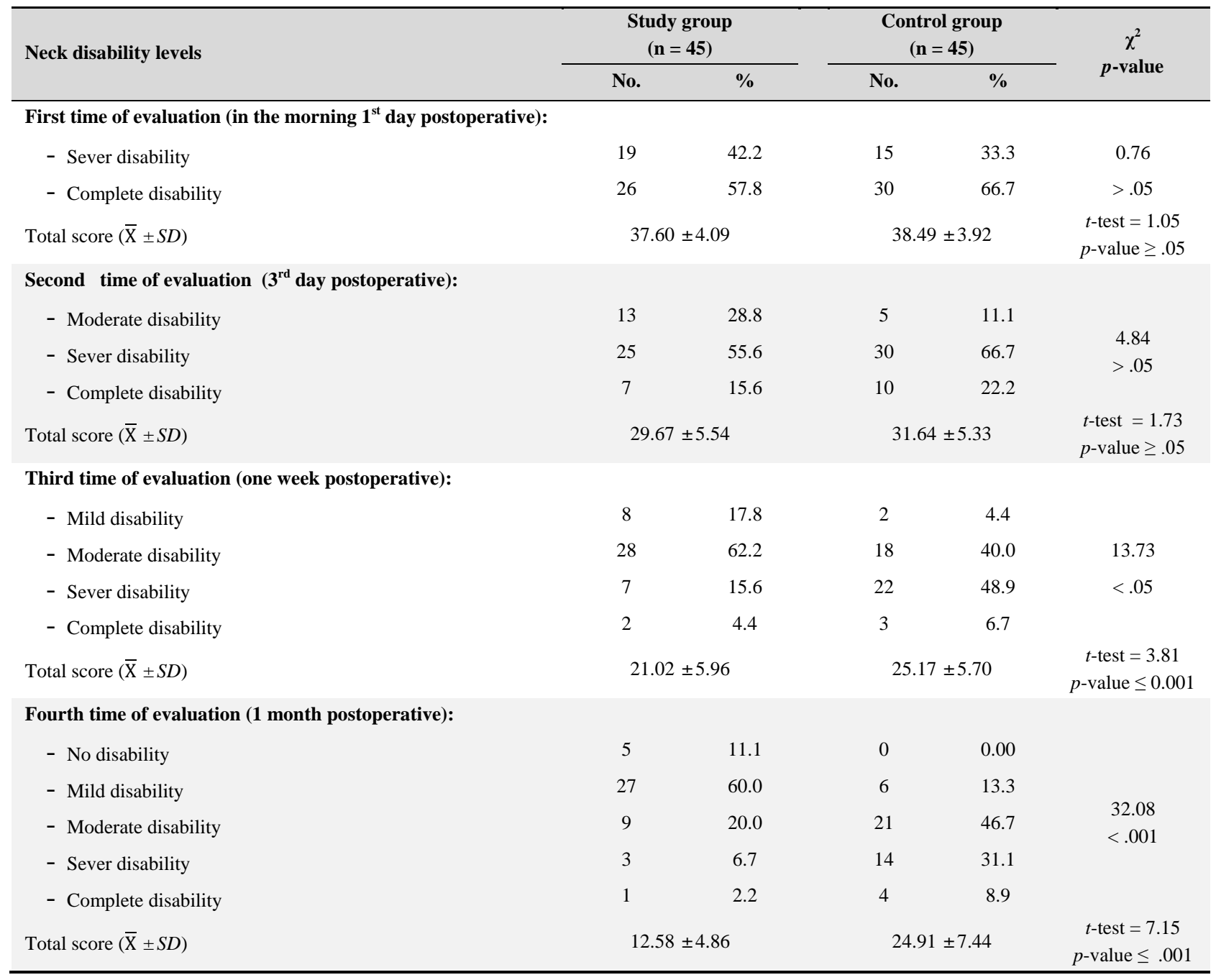

Table 4 describes that most of the patients from the study and the control groups ( $86.7 \%$ and $91.1 \%$ respectively) had a severe level of pain at pre-intervention in the first time of evaluation; while in the second time of evaluation postintervention $(64.4 \%)$ and $(77.8 \%)$ of study and control group respectively had severe pain while at the third time of evaluation post-intervention, $26.7 \%$ from study group had severe pain in contrast to $62.2 \%$ for control group had severe pain. Moreover, at the fourth time of evaluation post-intervention, more than half of the study group $(68.9 \%)$ had mild pain while only (20\%) of the control group had mild level of pain and still $(28.9 \%)$ had severe pain. The difference between study and control group wasn't statistically significant at the first and second time of evaluation as $p$-value $>.05$ while statistically significant at the third time of evaluation as $p$-value $<.05$ and highly statistically significant at the fourth time of evaluation as $p$-value $<.001$. 
Table 4. Pain levels of study and control groups at different times of evaluation

\begin{tabular}{|c|c|c|c|c|c|}
\hline \multirow{2}{*}{ Pain levels } & \multicolumn{2}{|c|}{ Study group $(n=45)$} & \multicolumn{2}{|c|}{ Control group $(n=45)$} & \multirow{2}{*}{$\begin{array}{c}\chi^{2} \\
p \text {-value }\end{array}$} \\
\hline & No. & $\%$ & No. & $\%$ & \\
\hline \multicolumn{6}{|c|}{ First time of evaluation (in the morning $1^{\text {st }}$ day postoperative): } \\
\hline - Moderate & 6 & 13.3 & 4 & 8.9 & 0.45 \\
\hline - Sever & 39 & 86.7 & 41 & 91.1 & $>.05$ \\
\hline Total score $(\overline{\mathrm{X}} \pm S D)$ & \multicolumn{2}{|c|}{$8.84 \pm 1.35$} & \multicolumn{2}{|c|}{$9.24 \pm 1.13$} & $\begin{array}{c}t \text {-test }=1.53 \\
p \text {-value }>.05\end{array}$ \\
\hline \multicolumn{6}{|c|}{ Second time of evaluation ( $3^{\text {rd }}$ day postoperative): } \\
\hline - Moderate & 16 & 35.6 & 10 & 22.2 & 1.95 \\
\hline - Sever & 29 & 64.4 & 35 & 77.8 & $>.05$ \\
\hline Total score $(\overline{\mathrm{X}} \pm S D)$ & \multicolumn{2}{|c|}{$6.47 \pm 1.44$} & \multicolumn{2}{|c|}{$7.00 \pm 1.24$} & $\begin{array}{c}t \text {-test }=1.88 \\
p \text {-value } \geq .05\end{array}$ \\
\hline \multicolumn{6}{|c|}{ Third time of evaluation (one week postoperative): } \\
\hline - Mild & 13 & 28.9 & 4 & 8.9 & 12.65 \\
\hline - Moderate & 20 & 44.4 & 13 & 28.9 & $<0.05$ \\
\hline - Sever & 12 & 26.7 & 28 & 62.2 & \\
\hline Total score $(\overline{\mathrm{X}} \pm S D)$ & \multicolumn{2}{|c|}{$4.38 \pm 1.29$} & \multicolumn{2}{|c|}{$5.40 \pm 1.52$} & $\begin{array}{c}t \text {-test }=3.21 \\
p \text {-value } \leq .05\end{array}$ \\
\hline \multicolumn{6}{|c|}{ Fourth time of evaluation ( 1 month postoperative): } \\
\hline - Mild & 31 & 68.9 & 9 & 20.0 & 23.62 \\
\hline - Moderate & 12 & 26.7 & 23 & 51.1 & $<0.001$ \\
\hline - Sever & 2 & 4.4 & 13 & 28.9 & \\
\hline Total score $(\overline{\mathrm{X}} \pm S D)$ & \multicolumn{2}{|c|}{$2.62 \pm 0.82$} & \multicolumn{2}{|c|}{$4.69 \pm 1.78$} & $\begin{array}{c}t \text {-test }=5.91 \\
p \text {-value } \leq .001\end{array}$ \\
\hline
\end{tabular}

Table 5. Correlation between pain score and neck disability score of study group at different times of evaluation

\begin{tabular}{lcc}
\hline Neck disability & $\boldsymbol{R}$ & $\boldsymbol{p}$-value \\
\cline { 2 - 3 } & 0.265 & $>.05$ \\
\hline $\begin{array}{l}\text { First evaluation time } \\
\left(1^{\text {st }} \text { day postoperative }\right)\end{array}$ & 0.325 & $<.05$ \\
$\begin{array}{l}\text { Second evaluation time } \\
\left(3^{\text {rd }} \text { day postoperative }\right)\end{array}$ & 0.507 & $<.001$ \\
$\begin{array}{l}\text { Third evaluation time } \\
\text { (one week postoperative) }\end{array}$ & 0.655 & $<.001$ \\
$\begin{array}{l}\text { Fourth evaluation time } \\
(1 \text { month postoperative })\end{array}$ & & \\
\hline
\end{tabular}

Note. $R$ : Pearson's correlation coefficient

Table 5 illustrates the correlation between pain score and a neck disability score of the study group at different times of evaluation. There was no statistically significant positive correlation between pain score and neck disability score at pre-intervention in the first time of evaluation, while there was a statistically significant positive correlation between pain score and neck disability score at post-intervention at the second time of evaluation as $p$-value $<.05$ and highly statistically significant positive correlation between pain score and neck disability score at post-intervention at the third and fourth times of evaluation as $p$-value $<.001$.

Table 6. Correlation between pain score and compliance score of study group at different times of evaluation

\begin{tabular}{lcc}
\hline \multirow{2}{*}{ Compliance } & \multicolumn{2}{c}{ Pain } \\
\cline { 2 - 3 } & $\boldsymbol{R}$ & $\boldsymbol{p}$-value \\
\hline $\begin{array}{l}\text { First evaluation time } \\
\left(1^{\text {st }} \text { day postoperative }\right)\end{array}$ & -0.193 & $>.05$ \\
$\begin{array}{l}\text { Second evaluation time } \\
\left(3^{\text {rd }} \text { day postoperative }\right)\end{array}$ & -0.375 & $<.05$ \\
$\begin{array}{l}\text { Third evaluation time } \\
\text { (one week postoperative })\end{array}$ & -0.491 & $<.05$ \\
$\begin{array}{l}\text { Fourth evaluation time } \\
(1 \text { month postoperative })\end{array}$ & -0.505 & $<.001$ \\
\hline Note. $R$ : Pearson's correlation coefficient & &
\end{tabular}

Table 6 reveals a correlation between pain score and a compliance score of the study group at different times of evaluation. There was no statistically significant negative correlation between pain score and compliance score at pre-intervention in the first time of evaluation, while there was a statistically significant negative correlation between pain score and compliance score at post-intervention at the second and third time of evaluation as $p$-value $<.05$ and highly statistically significant negative correlation between pain score and compliance 
score at post-intervention at the fourth time of evaluation as $p$-value $<.001$.

Table 7 illustrates the correlation between the neck disability score and a compliance score of the study group at different times of evaluation. There was no statistically significant negative correlation between neck disability score and compliance score at pre-intervention in the first time of evaluation, while there was a statistically significant negative correlation between the neck disability score and a compliance score at post-intervention at the second time of evaluation as $p$-value $<.05$ and highly statistically significant negative correlation between neck disability score and compliance score at postintervention at the third and the fourth times of evaluation as $p$-value $<.001$.

Table 7. Correlation between neck disability score and compliance score of study group at different times of evaluation

\begin{tabular}{lcc}
\hline \multirow{2}{*}{ Compliance } & \multicolumn{2}{c}{ Neck disability } \\
\cline { 2 - 3 } & $\boldsymbol{R}$ & $\boldsymbol{p}$-value \\
\hline $\begin{array}{l}\text { First evaluation time } \\
\left(1^{\text {st }} \text { day postoperative }\right)\end{array}$ & -0.269 & $>.05$ \\
$\begin{array}{l}\text { Second evaluation time } \\
\left(3^{\text {rd }} \text { day postoperative }\right)\end{array}$ & -0.311 & $<.05$ \\
$\begin{array}{l}\text { Third evaluation time } \\
\text { (one week postoperative) }\end{array}$ & -0.503 & $<.001$ \\
$\begin{array}{l}\text { Fourth evaluation time } \\
(1 \text { month postoperative })\end{array}$ & -0.760 & $<.001$ \\
\hline Note. $R$ : Pearson's correlation coefficient & &
\end{tabular}

\section{Discussion}

Preoperative nursing care should cover the comprehensive needs of the patient, improving the patient's confidence to face surgery, and back to regular daily living activities. ${ }^{[23]}$ The aim of the present research is to investigate the effect of neck range of motion exercises on neck disability and pain among patients undergoing thyroidectomy.

\subsection{Regarding demographic characteristics of the pa- tients}

Concerning age, the current research presented that the mean age for the study group was $39.82 \pm 10.99$ years while the control group was $38.93 \pm 10.88$ years. These findings supported by Abd-El Mohsen and Ahmed, ${ }^{[24]}$ stated that the mean age of the studied subjects was $39.47 \pm 10.23$ years. As well as, Mishra et al. ${ }^{[25]}$ illustrated that, thyroid disorders are very common in middle-aged and older adults. Moreover, El-Khateeb et al. ${ }^{[26]}$ reported that the mean age of the subjects undergoing thyroidectomy was $37.53 \pm 10.48$. But the current result not matched with Aysun et al., ${ }^{[6]}$ who founded that the mean ages of the group I and group II subjects were
$51.6 \pm 14.9$ and $49.2 \pm 16.3$ years, respectively.

Regarding gender the majority of both group patients were females; the finding supported with the research finding conducted by Aysun et al. ${ }^{[6]}$ and Abd-El Mohsen and Ahmed ${ }^{[24]}$ who showed that the majority of studied subjects were females. Moreover, Hariadha et al. ${ }^{[27]}$ revealed that thyroid diseases were found among womens more than males. Chandrasekhar et al. ${ }^{[2]}$ reported that thyroidectomy is conducted on both male and female subjects while it is more common on female. Moreover, Vanderpump ${ }^{[28]}$ also mentioned that the majority of women undergo thyroidectomy as compared to males. ${ }^{[3,5]}$

As regards, education level and occupation the majority of both study and control groups had secondary education and had worked. The current research finding disagreed with Aysun et al., ${ }^{[6]}$ who founded that the majority of the subjects had a primary school. Moreover, Abd-El Mohsen and Ahmed ${ }^{[24]}$ mentioned that more than two-thirds of subjects in the study group and half in the control group were illiterate and more than half of the subjects in both groups were housewives. Also, the current research result was not inconsistent with Desoky et al., ${ }^{[14]}$ who showed that more than two-thirds of the studied subjects were illiterate and a little more than three quarters were housewives. The differences in the findings may be due to the nature and community characteristics of the studied subjects.

Regarding the medical history and health habits for both groups, approximately one- quarter of the study group and one-third of the control group had diabetes mellitus, as well as the majority of both groups had hypertension. The findings were consistent with Abd-El Mohsen and Ahmed ${ }^{[24]}$ who demonstrated that more than one-quarter of the study and the control group was having diabetes, and the third of the study group had hypertension. In addition, the finding was consistent with Al-Geffari et al., ${ }^{[29]}$ who reported that diabetic patients have a susceptibility to various types of thyroid disorders. In the same context, Vargas et al. ${ }^{[30]}$ mentioned that hormones of the thyroid gland affect the development and/or maintenance of different forms of arterial hypertension.

Concerning type of the operation, the current research findings demonstrated that the majority of both study and control patients underwent subtotal thyroidectomy. The finding agreed with Desoky et al., ${ }^{[14]}$ who carried out their study in the general surgery department at Assiut University Hospital, who mentioned that subtotal thyroidectomy was the most frequently performed procedure for the majority of subjects. as well as, the current finding is consistent with Memon et al., ${ }^{[31]}$ who assured that the most frequent surgical pro- 
cedure was performed subtotal thyroidectomy followed by hemithyroidectomy.

The current research findings not matched with Abd-El Mohsen and Ahmed ${ }^{[24]}$ who presented that more than half of subjects in the study group and less than half in the control group underwent total thyroidectomy. Also, the study finding disagreed with Abboud et al., ${ }^{[32]}$ who found that the majority of the studied patients performed total thyroidectomy.

As regards health habits the current study finding mentioned that the majority of both group subjects were drinking caffeinated beverages like tea and coffee and nonsmokers. The finding is in the same line with Ahmed et al., ${ }^{[33]}$ who revealed that the majority of the subjects were nonsmokers due to the majority of the studied sample were women. As well as, Abd-El Mohsen and Ahmed ${ }^{[24]}$ who found that less than half of the subjects in the study and control group used to consume tea or coffee but disagreed with the current finding because one-fifth of both studied group were smokers. In addition, the finding is not consistent with Wiersinga ${ }^{[34]}$ who mentioned that smoking has a distinct relation with thyroid function and size in healthy persons.

\subsection{Concerning pain and neck disability}

Regarding neck pain and neck disability index, the results of the current research illustrated that neck pain and related disability significantly decreased in the study group in two times intervals 7th day (a week) third time of evaluation and one month (four weeks) fourth time of evaluation after thyroidectomy than in the control group. The current finding of the research was consistent with Abd-El Mohsen and $\mathrm{Ahmed}^{[24]}$ who stated that the findings of their research showed that neck pain and related disability significantly decreased in the study group after one-week post thyroidectomy than in the control group. In addition, the current findings matched with Takamura et al., ${ }^{[12]}$ who stated that discomfort in the neck was less in the study group one week after total thyroidectomy. As well as, the finding of the current study is in the same line with Jang et al., ${ }^{[35]}$ who revealed that movement limitations and discomfort in the neck were much lesser in the study group during the evaluations that made two weeks following thyroidectomy because the subjects are encouraged preoperatively to practice five replicates of every stretching exercise, three times daily as well as they reported that the patients can practice these exercises on the first day of the postoperative period at the morning.

Moreover, in the current research, there was a significant statistical difference between the study and the control groups in terms of neck disability and neck pain in one month following the total thyroidectomy. The current research finding is inconsistent with Jang et al., ${ }^{[35]}$ who didn't find any significant difference between study and control groups in terms of neck discomfort and range of motion one and 3 months after thyroidectomy with demonstrated that this is most likely due to that neck disability and pain ameliorates naturally within 1 month following a thyroid surgical removal.

The findings of the current research are inconsistent with Ayhan et al., ${ }^{[10]}$ who presented that there were no significant differences between the stretching neck exercises group and the control group regarding neck pain and disability or neck sensitivity and movement limitation 1 month after a thyroid surgical removal because they illustrated that patients experience neck movement limitation and tend not to move their necks following a thyroidectomy. Neck movements are limited because of the presence of rigidity which causes neck disability and pain but it decreases naturally one month following a thyroid surgical removal.

In the same context, the current finding of the study is in the same line with Ahmed, Mekkawy, and Mojelly ${ }^{[33]}$ reported that thyroidectomy ends with discomfort symptoms in patients for the rest of their life, the patients try to live their life with discomfort in their neck. These patients frequently report discomfort in their neck like stress in the neck, pain, stiffness around the shoulder, and restriction in neck and shoulder range of motion difficulties.

Also, Mage ${ }^{[36]}$ reported that a limited range of motion shows a joint that has a reduction in its ability to move. The motion may be limited because of a problem within the joint, swelling of tissue around the joint, muscles stiffness, or pain. Moreover, Abd-El Mohsen and Ahmed ${ }^{[24]}$ mentioned that discomfort symptoms occur in patients with thyroidectomy because patients' necks remain in a hyperextended position during the prolonged operation and during the early postoperative period. As well as, Rutledge et al., ${ }^{[37]}$ who concluded that neck movements and exercise are recommended to avoid negative experiences following thyroidectomy.

As well as, Ayhan et al. ${ }^{[10]}$ reported that the planned and regular neck stretching exercises started immediately the following thyroidectomy and significantly decrease short-term neck pain as well as disability symptoms. Moreover, neck stretching exercises started in the early post-thyroidectomy period and have no negative effect on the healing of the wound.

\section{Conclusions}

Patient compliance with a range of motion exercises significantly improves neck movement in order to be able to carry out daily life activities and reducing pain for the study group in comparison with the control group.

ISSN 2324-7940 E-ISSN 2324-7959 


\section{RECOMMENDATIONS}

In light of the findings obtained from the current study the following recommendations are derived and suggested in nursing.

1) Recommendation for nursing practice:

- Nurses can be taught about neck range of motion exercises; and it can be practiced in the clinical setting.

- Nurses who work in the general surgery department should include neck range of motion exercises when providing the care and follow up protocol for the patients undergoing thyroidectomy.

2) Recommendations for nursing education:

- The neck range of motion exercises for the patients un- dergoing thyroidectomy can be included in the nursing curriculum.

- Nursing students can be taught about neck range of motion exercises for the patients undergoing thyroidectomy.

3) Recommendations for future nursing researches

- Replication of the study using a larger probability sample from different geographical areas to attain more generalizable results.

\section{CONFLicts OF INTEREST Disclosure}

The authors declare they have no conflicts of interest.

\section{REFERENCES}

[1] Lancet Commission on Global Surgery. Number of surgical procedures (per 100,000 population). Google Scholar. 2018.

[2] Chandrasekhar SS, Randolph GW, Seidman MD, et al. Clinical practice guideline: improving voice outcomes after thyroid surgery Otolaryngology. Head and Neck Surgery. 2013; 148(6): S1-S37. PMid: 23733893. https://doi.org/10.1177/0194599813487301

[3] Lee DY, Seok J, Jeong WJ, et al. Prediction of thyroid hormone supplementation after thyroid lobectomy. Journal of Surgical Research. 2015; 193(1): 273-78. PMid: 25088372. https ://doi.org/10.1 $016 / j \cdot j$ ss.2014.07.003

[4] Adam MA, Thomas S, Youngwirth L, et al. Is there a minimum number of thyroidectomies a surgeon should perform to optimize patient outcomes? Ann Surg. 2009; 265(2): 402-7. PMid: 28059969. https://doi.org/10.1097/SLA.0000000000001688

[5] Tidy C. Thyroid disease and surgery. Egton Medical Information. 2011.

[6] Genc A, Genc C, Çelik SU, et al. The effects of cervical kinesiotaping on neck pain, range of motion, and disability in patients following thyroidectomy: a randomized, double-blind, sham-controlled clinical trial. Turk J Med Sci. 2019; 49: 1185-91. PMid: 31340634. https://doi.org/10.3906/sag-1812-55

[7] D’Orazi V, Sacconi A, Trombetta S, et al. May predictors of difficulty in thyroid surgery increase the incidence of complications? Prospective study with the proposal of a preoperative score. BMC Surgery. 2019; 18(116): 438. PMid: 31074389. https://doi .org/10.118 6/s12893-018-0447-7

[8] Randolph GW, Shah JP. Thyroid surgery: unilateral thyroidectomy: indications and technique In: Randolph, GW, Surgery of the Thyroid and Parathyroid Glands. Philadelphia: Saunders; 2016. 271 p.

[9] Ayhan H, Tastan S, Iyigün E, et al. The effectiveness of neck stretching exercises following total thyroidectomy on reducing neck pain and disability: a randomized controlled trial. Worldviews. Evid Based Nurs. 2018; 13(3): 224-31. PMid: 26773539. https://doi.org/10.1111/wvn.12136

[10] Ayhan H, Tastan S, Iyigun E, et al. The effectiveness of the neck exercises following total thyroidectomy on reducing neck pain and disability: Randomized controlled trial. Cancer Nurs. 2015; 38(4): 224-31. PMid: 26773539. https://doi.org/10.1111/wvn.12136

Published by Sciedu Press
[11] Takamura Y, Miyauchi A, Tomoda C, et al. Stretching exercises to reduce symptoms of postoperative neck discomfort after thyroid surgery: prospective randomized study. World Journal of Surgery. 2018; 29(6): 775-79. PMid: 16078129. https://doi.org/10.1 $007 / \mathrm{s} 00268-005-7722-3$

[12] Perera A, Patel S, Law N. Thyroid surgery as a 23-hour stay procedure. Ann Royal College Surgeons England. 2018; 96: 284-8. PMid: 24780020. https://doi.org/10.1308/003588414X13 814021679997

[13] Desoky AA, Mohamed MA, Ahmed MT, et al. Assessment of Nursing Performance for Patients Undergoing Thyroidectomy. AAMJ. 2009; 7(2): 1-19.

[14] Shenouda MMS. Efficacy of Stretching Exercises Versus Postisometric Relaxation Technique on Pain, Functional Disability and Range of Motion in Patients with Cervical Spondylosis. A Randomized controlled trial. Bulletin of Faculty of Physical Therapy. 2012; 17(2): 74-80.

[15] Jacobs V. Informational needs of surgical patients following discharge. Applied Nur Res. 2019; 13: 12-8. https ://doi .org/10.1 016/S0897-1897(00) 80014-2

[16] Terris DJ, Snyder S, CarneiroPla D, et al. American thyroid association statement on outpatient thyroidectomy. Thyroid. 2016; 23: 1193202. PMid: 23742254 . https ://doi .org/10.1089/thy. 2013.0 049

[17] Berman A, Snyder S, Frandsen G. Kozier \& Erb's fundamentals of nursing: concepts, practice, and process, 10th ed., London, Julie Levin Alexander. 2016; 1012-1013 p.

[18] Bain G, Kuwahata H, Raymod B, et al. Tea Tree / Hydrogel Dressings Used in Wound Care. A Report for the Rural Industries Research and Development Corporation. 2005. Available from: www.ride.gov.au/fullreports/indx.html/

[19] Vernon H, Mior S. The Neck Disability Index: a study of reliability and validity. J Manipulative Physiol Ther. 1991; 14(7): 409-15. https://doi.org/10.1037/t35122-000

[20] Boonstra A, Schiphorts P, Henrica R, et al. Reliability and Validity of the Visual Analogue Scale for Disability in Patients with Chronic Musculoskeletal Pain. International Journal of Rehabilitation Research. 2008; 31(2): 165-9. PMid: 18467932. https: //doi.org/10.1097/MRR.0b013e3282fc0f93 
[21] Macdermid JC, Walton DM, Avery S, et al. Measurement properties of the neck disability index a sustematic review. Journal of Orthopedic and Sports Physical Therapy. 2009; 39(5): 400-17. PMid: 19521015. https://doi.org/10.2519/jospt.2009.2930

[22] Gruy S, Thomas ST. Exercise advice for patients recovering from thyroid surgery. World Journal of Pharmaceutical Research SJIF. 2019; 7(17): 350-55.

[23] Chen HC, Wang MH. An Experience in Perioperative Nursing Care for a Patient Who Underwent Total Thyroidectomy. Tzu Chi Nursing Journal. 2011; 10(5): 98-107. https ://doi.org/10.1016/j.tc $\mathrm{mj} .2011 .05 .004$

[24] Abd-El Mohsen S, Amed N. Effect of teaching patients neck stretching exercises on neck pain and disability following thyroidectomy. Journal of Nursing Education and Practice. 2018; 8(1): 107. https: //doi.org/10.5430/jnep.v8n1p107

[25] Mishra A, Sabaretnam M, Chand G, et al. Quality of life (QoL) in patients with benign thyroid goiters (pre-and post-thyroidectomy): a prospective study, World J Surg. 2013; 37(10): 1-8. PMid: 23838927. https://doi.org/10.1007/s00268-013-2133-3

[26] El-Khateeb AI, Ali HA, Makhlouf GA, et al. Total extracapsular thyroidectomy versus subtotal thyroidectomy in nonmalignant goiter. The Egyptian Journal of Surgery. 2015; 34(3): 166. https: //doi.org/10.4103/1110-1121.163120

[27] Hariadha E, Sulaiman SAS, Gillani SW, et al. A preliminary study on post-surgical complications after thyroidectomy in Pulau Pinang, Malaysia. International Journal of Pharmacy \& Life Sciences. 2013; 4(6): 2717-21.

[28] Vanderpump MP. The epidemiology of thyroid disease. Br Med Bull. 2011; 99(1): 39-51. PMid: 21893493. https ://doi.org/10.109 $3 / \mathrm{bmb} / 1 \mathrm{dr} 030$

[29] Al-Geffari M, Ahmad NA, Al-Sharqawi AH. Risk factors for thyroid dysfunction among type 2 diabetic patients in a highly diabetes mel- litus prevalent society. International Journal of Endocrinology. 2013. PMid: 24454365. https : //doi.org/10.1155/2013/417920

[30] Vargas F, Moreno JM, Rodríguez-Gómez I. Vascular and renal function in experimental thyroid disorders. European Journal of Endocrinology. 2006; 154(2): 197-212. PMid: 16452532. https : //doi.org/10.1530/eje.1.02093

[31] Memon AA, Junejo A, Balouch TA. Postoperative Complications of Thyroidectomy. An experience at Tertiary Care Hospital. Medical Channel. 2012; 18(4): 4-11.

[32] Abboud B, Sleilaty G, Rizk H. Safety of thyroidectomy and cervical neck dissection without drains. Canadian Journal of Surgery. 2012; 55(3): 199. PMid: 22449723. https://doi.org/10.1503/cjs. 025710

[33] Ahmed AM, Mekkawy MM, Mojelly AM. Outcomes of Clinical Pathway Implementation for Patients Undergoing Thyroidectomy, Doctoral thesis. 2016.

[34] Wiersinga WM. Smoking and thyroid. Clinical Endocrinology. 2013; 79(2): 145-51. PMid: 23581474. https://doi.org/10.1111/ce n. 12222

[35] Jang JY, Chang YS, Kim EH. Early neck exercises to reduce postthyroidectomy syndrome after uncomplicated thyroid surgery: A prospective randomized study. Journal of Korean Thyroid Association. 2014; 7(1): 70-6. https : //doi .org/10.11106/jkta. 2014 .7 .1 .70

[36] Magee DJ. Primary care assessment. In:Orthopedic Physical Assessment. 6th ed. St Louis, MO: Elsevier Saunders, chap 17. Limited range of motion. 2014.

[37] Rutledge J, Siegel E, Belcher R. Barriers to samedaydischarge of patients undergoing total and completion thyroidectomy. Otolaryngology-Head Neck Surgery. 2014; 150: 770-4. PMid: 24493789. https://doi.org/10.1177/0194599814521568 